\title{
Modal ferroviário e transporte de soja no MATOPIBA
}

Railways and the transport of soybean in MATOPIBA

\author{
João Victor Brugnera ${ }^{1}$; Flávio Carlos Dalchiavon²*
}

${ }^{1}$ Bacharel em Comércio Exterior, Rua Glauber Rocha, 1254, Jardim Paraíso - 47850-000 - Luís Eduardo Magalhães, BA, Brasil

2 Engenheiro Agrônomo, Doutor em Agronomia, Instituto Federal de Mato Grosso, Campus Campo Novo do Parecis, Rodovia MT 235, km 12, s/n, Caixa Postal n 100, Zona Rural - 7360-000 - Campo Novo do Parecis, MT, Brasil <flavio.dalchiavon@cnp.ifmt.edu.br>

\begin{abstract}
Resumo
A produção brasileira de soja desenvolve-se em ritmo acelerado e novas regiões agrícolas são formadas de acordo com a necessidade e oportunidade de expansão. As novas fronteiras agrícolas trazem consigo grandes desafios, principalmente referentes à infraestrutura logística disponível em cada região para o escoamento da safra. Torna-se fundamental conhecer essa estrutura a fim de planejar investimentos nessas regiões, calcular e estimar custos de compra e venda de grãos e insumos, tanto para produtores, quanto para cooperativas, revendas e tradings. Objetivou-se com este estudo descrever o atual escoamento rodoviário e ferroviário de soja do MATOPIBA e a potencialidade da expansão do modal ferroviário voltado à exportação de grãos, tão quanto seus benefícios e entraves para os que atuam na cadeia da soja na região. Adotou-se o método de pesquisa qualitativa com embasamento em publicações diversas. Observou-se que para atingir níveis de competitividade internacional e desenvolver áreas agrícolas mais distantes dos portos, as novas regiões agrícolas precisam de apoio governamental e privado para superar seus gargalos logísticos e investir em modais alternativos, como a implantação de um sistema ferroviário interligando o interior aos portos brasileiros. Comprovadamente, o modal ferroviário é indicado para o escoamento de soja, com menores custos e maior segurança no transporte, resultando em maiores investimentos e desenvolvimento para toda a cadeia de soja das novas fronteiras agrícolas brasileiras.
\end{abstract}

Palavras-chave: agronegócio brasileiro, ferrovia, fronteira agrícola, logística

\begin{abstract}
Brazilian soybean production develops in a fast pace and new agricultural regions are formed according to the necessity and opportunities for expansion, bringing with them significant challenges, especially regarding the logistics infrastructure in each place, to transport the crop from the field to the ports. It is crucial to know the local structure to plan new investments in these regions, as to calculate and estimate the market cost of grains and inputs, whether for producers, cooperatives, resellers and tradings. This study aimed to describe the current soybean flow in MATOPIBA, both by road and railways, the potentiality to expand the transportation of grains by railroads, and the benefits and obstacles for those who operate with soybean in the region. The method of research adopted was qualitative, based in diverse publications. It was noted that, to achieve levels of international competitiveness and to develop the production areas that are distant from the ports, new agricultural regions rely on government and private support to overcome their logistical issues and invest in alternative logistics, such as the rail system, connecting the interior to the Brazilian ports. The soybean transport by railroad has proven to be a good alternative for having low costs and risks, resulting in greater investments and development for the entire soybean chain of the new Brazilian agricultural frontiers.
\end{abstract}

Keywords: Brazilian agribusiness, railway, agricultural frontier, logistics

\section{Introdução}

A região conhecida oficialmente como MATOPIBA é formada pelos estados do Maranhão, Tocantins, Piauí e Bahia e abrange grande parte do Cerrado das regiões Norte e Nordeste do Brasil. Sua delimitação territorial foi oficialmente determinada pelo Plano de Desenvolvimento Agropecuário do MATOPIBA, elaborado pelo Ministério da Agricultura, Pecuária e Abastecimento [MAPA], oficializado por meio da portaria $\mathrm{N}^{\circ} 244$, de 12 de novembro de 2015 publicada no Diário Oficial da União, correspondendo a setenta e três milhões de hectares. A região possui aproximadamente 324 estabelecimentos agrícolas e foi responsável pela produção de $32 \%$ do algodão e $9,4 \%$ dos grãos brasileiros na safra 2014/15. Ainda em vasta expansão, com a adoção de alta tecnologia, pesquisa de variedades de sementes e manejo de solo adequado para a região, o MAPA prevê um aumento de 16\% na 
produção de grãos entre as safras 2014/15 e 2024/25, acompanhado de um aumento de $18,7 \%$ da área plantada (BRASIL, 2015; MAPA, 2015).

O grão com maior destaque em área, produção e exportação pelos quatro estados que compõem o MATOPIBA é a soja. Sua produção na safra 2014/15 foi de 10,5 milhões de toneladas, sendo exportados $60 \%$ de todo o volume, principalmente pelos portos de São Luís, Maranhão e Salvador, Bahia (CONAB, 2016).

$\mathrm{O}$ crescimento da região vem atraindo inúmeros investimentos, tanto interno/externo quanto público/privado, garantindo melhor estruturação de produção, comercialização e escoamento à região, além de gerar emprego e renda para a população do MATOPIBA. Entre os investimentos em infraestrutura, destaca-se a implantação de novas rotas ferroviárias para o escoamento da safra, ligando as regiões produtoras aos portos do Nordeste brasileiro. A principal ferrovia instalada é a Ferrovia Norte-Sul, com trechos administrados pela empresa Valor da Logística Integrada [VLI], que conta com $720 \mathrm{~km}$ de extensão em operação, ligando os municípios de Porto Nacional, Tocantins à Açailândia, Maranhão, integrando-se à ferrovia Estrada de Ferro Carajás, com destino ao Porto de Itaqui, em São Luís, Maranhão, seu ponto final, aonde a soja é armazenada e carregada em navios para exportação.

Outras futuras opções de escoamento da safra por ferrovias no MATOPIBA estão em fase de estudo, licitações ou em obras, sendo a Ferrovia Transnordestina, interligada com a Ferrovia Norte-Sul, que contará como opções para descarga os Portos de Pecém, Ceará e de Suape, Pernambuco, e a Ferrovia de Integração Oeste-Leste, também interligada à Ferrovia Norte-Sul em Figueirópolis - TO, conectando as regiões produtoras do Sul do Tocantins e Oeste da Bahia, no Porto de Ilhéus (Branco e Caixeta Filho, 2011).

Assim, objetivou-se com este estudo descrever o atual escoamento rodoviário e ferroviário de soja do MATOPIBA e a potencialidade da expansão do modal ferroviário voltado à exportação de grãos, tão quanto seus benefícios e entraves para os que atuam na cadeia da soja na região.

\section{Material e Métodos}

Este trabalho apresenta a sistemática, os custos e os benefícios do transporte ferroviário da soja nas ferrovias que estão sendo implantadas no MATOPIBA, região agrícola formada pelos estados do Maranhão, Tocantins, Piauí e Bahia, que se destacam pelo alto potencial na produção de grãos, como mencionado por Branco et al. (2010). As ferrovias irão impactar também as regiões produtoras de estados vizinhos, como o Mato Grosso, Pará e Goiás, além de possibilitar maior movimentação nos portos do Ceará e Pernambuco.
Como referenciais numéricos, foram levantados dados alusivos à safra de soja dos anos 2014/2015, considerando como ano safra os períodos de semeadura (outubro a janeiro) e colheita (fevereiro a maio) da região, assim como dados históricos referentes à criação de cada ferrovia até seu atual status de implantação.

A metodologia utilizada foi baseada no método qualitativo, a partir de informações acerca dos temas fronteira agrícola, agronegócio, commodities, logística, corredor de exportação, características dos modais, dentre outros, coletadas por meio de referenciais teóricos (artigos científicos, sites governamentais, livros etc.). Foram utilizados meios bibliográficos e documentais para coleta de dados, com base em dados secundários existentes e disponibilizados por órgãos e autores especializados no assunto, como artigos científicos, legislações brasileiras, sites governamentais de pesquisa e entrevistas. Os fins da pesquisa foram exploratórios, proporcionando uma visão geral acerca dos objetivos propostos. As informações coletadas foram apresentadas na forma de textos descritivos, tabelas e figuras.

\section{Resultados e Discussão}

\section{A cadeia produtiva da soja no MATOPIBA}

O grão da soja é utilizado mundialmente de diversas maneiras, tanto para o consumo humano e animal como para a geração de energia a partir do biodiesel. Seu subproduto, o farelo, é utilizado basicamente como suplemento de alto valor proteico para a criação de animais (Missão, 2006).

A região conhecida como MATOPIBA desenvolveu-se a partir da chegada de migrantes oriundos principalmente do Sul do Brasil na década de 1970. Foram incentivados por políticas e programas governamentais (Silva et al., 2015) voltados ao desenvolvimento de novas áreas no Cerrado do Norte e Nordeste do Brasil, como o Programa de Desenvolvimento do Cerrado [Polocentro], Programa de Terras e de Estímulo à Agroindústria do Norte e do Nordeste [Polonordeste] e o Programa de Cooperação Nipo-Brasileira de Desenvolvimento Agrícola da Região do Cerrado [Prodecer]. Estes ofereceram benefícios a produtores, como crédito agrícola e menor preço para compra de terra, para a exploração agrícola na região do Cerrado dos estados do Maranhão, Tocantins, Piauí e Bahia (Matos e Pessôa, 2011; Alves, 2014; Barbosa et al., 2015).

Desde a chegada desses produtores, foi sendo estabelecida uma cultura empreendedora no campo, com a aplicação de alta tecnologia em insumos e maquinários, investimentos em abertura de áreas, correção de solo e irrigação. $\mathrm{O}$ resultado desse investimento somado a experiência dos produtores, resultou em uma das regiões de maior destaque na produção agrícola atual do Brasil, principalmente nas 
culturas de soja, milho e algodão (Branco et al., 2010; Branco e Caixeta Filho, 2011).

Devido ao alto grau de investimentos e a abertura de novas áreas, a região apresentou um crescimento na produção de grãos de $20 \%$ ao ano, contra a média nacional de 3,5\% ao ano, criando assim uma dinâmica diferenciada de crescimento econômico, onde segundo indicadores do Produto Interno Bruto [PIB] municipal de 2012. Destaca-se o crescimento dos municípios ligados ao agronegócio presentes na região do MATOPIBA em relação aos municípios de outras regiões e diferentes setores.

Com o grande crescimento agrícola e econômico da região e a necessidade de investimentos para continuar se desenvolvendo, fez-se necessária sua delimitação territorial por parte do Governo Federal, que foi oficializado pelo MAPA em 2015. Em parceria com o Grupo de Inteligência Territorial Estratégica da Embrapa [GITE] delimitou-se a região que abrange 73 milhões de hectares pelos quatro estados, formado por 31 microrregiões, 337 municípios e 5,9 milhões de habitantes (EMBRAPA, 2015) (Figura 1).

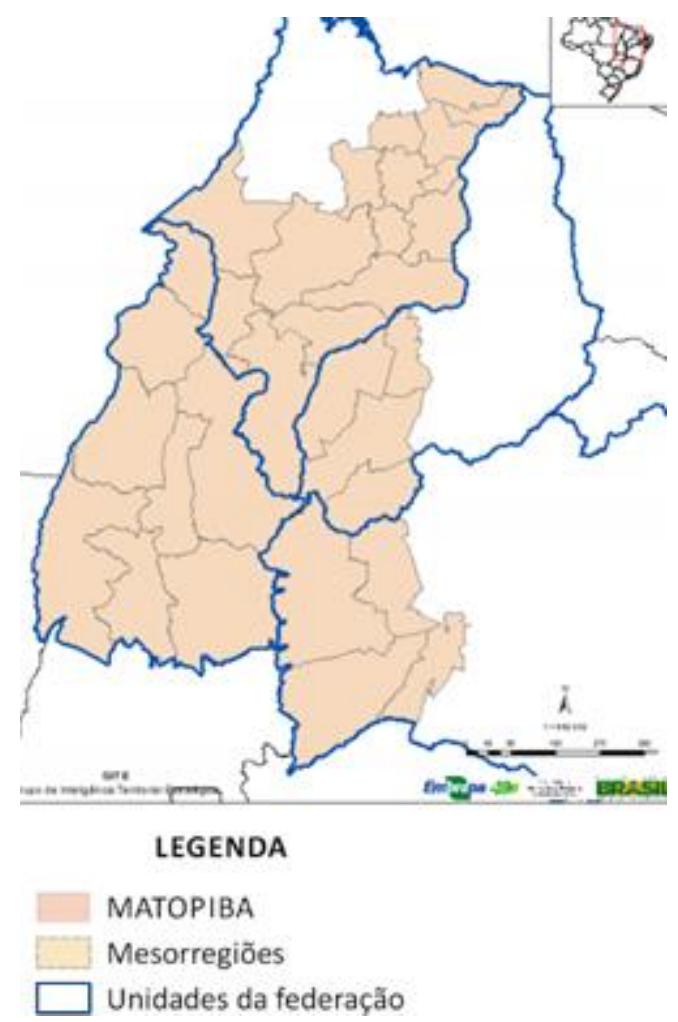

Figura 1. Delimitação territorial do MATOPIBA Fonte: EMBRAPA (2015)

Na safra 2014/15, o MATOPIBA somou 6,7 milhões de hectares semeados com arroz, algodão, milho, soja e sorgo, produzindo um total de 17,7 milhões de toneladas. A soja é a precursora dessa produção, ocupando 3,6 milhões de hectares, produzindo 10,5 milhões de toneladas, volume que representa $11 \%$ da produção nacional, incremento de $60 \%$ na área semeada e $64 \%$ na produção entre as safras 2010/11 e 2014/15.

Entre os estados que compõem a região, a Bahia possui a maior representatividade em produção de soja, com área de 1.422 mil hectares e produtividade média de 49 sacas de $60 \mathrm{~kg} \mathrm{ha}^{-1}$ na safra 2014/15, contra 850 mil hectares e 48,5 sacas há-1 do Tocantins, 749 mil hectares e 46 sacas ha $^{-1}$ do Maranhão e 674 mil hectares com 45 sacas ha $^{-1}$ do Piauí (CONAB, 2011; 2016).

A soja produzida no MATOPIBA é destinada principalmente para a produção de óleo vegetal, biodiesel e o mercado externo. Segundo dados da Associação Brasileira das Indústrias de Óleos Vegetais [ABIOVE], em 2014 a capacidade de processamento instalada das indústrias de óleo vegetal nos estados do Maranhão, Piauí e Bahia era de 10.991 toneladas por dia, correspondendo a $7 \%$ da capacidade brasileira. O estado do Tocantins conta com uma esmagadora de soja para a produção de biodiesel, com capacidade de processamento de 2.500 toneladas por dia (ABIOVE, 2015; SEAGRO, 2015).

A exportação é o principal destino da soja produzida. Segundo dados do Ministério do Desenvolvimento, Indústria e Comércio Exterior (MDIC, 2015), foram exportados entre fevereiro de 2014 a janeiro de 2015, 4,8 milhões de toneladas, com valor estimado de US\$2,4 bilhões "Free on Board" [FOB]. Os principais portos de origem foram o de São Luís, Maranhão, com $52 \%$ do volume exportado, e o de Aratu - Bahia, com 41\% do total.

As condições de entrega da soja seguem os mesmos parâmetros de outras regiões do Brasil, onde o escoamento dos lotes é definido na negociação entre o vendedor (produtores, corretores, cooperativas etc.) e o comprador (tradings, indústrias, comerciantes etc.). Pode ser negociada pelo vendedor a entrega da soja no armazém do comprador, que por sua vez leva o grão armazenado para a indústria ou para o porto, ou o comprador se compromete a retirar a soja da fazenda do produtor, levando diretamente ao destino adequado, podendo este utilizar os modais rodoviário e ferroviário, no caso do MATOPIBA.

Hoje, há duas rotas principais utilizadas no escoamento e exportação de soja no MATOPIBA. A primeira atende o Oeste da Bahia, o Sudeste do Tocantins e o Sul do Piauí, onde o grão é transportado até o porto de Salvador e em menores proporções ao porto de Ilhéus. A segunda rota é voltada ao Centro e Norte do Tocantins e Piauí e todo o Maranhão, onde a soja é transportada até o porto de Itaqui, em São Luís, Maranhão. A participação de outros portos ocorre em menores volumes (Tabela 1), conforme se observa nos dados das exportações (safra 2014/15). 
Tabela 1 Exportação de Soja do MATOPIBA por terminal portuário, entre fevereiro de 2014 a janeiro de 2015

\begin{tabular}{lccc}
\hline Estado de origem & Porto de destino & Volume exportado & Em relação à origem \\
\hline \multirow{3}{*}{ Maranhão } & & -1.376 .470 & 93 \\
& São Luís, MA & 57.447 & 4 \\
& Salvador, BA & 42.862 & 3 \\
& Barcarena, PA & 868.075 & 70 \\
\multirow{2}{*}{ Tocantins } & São Luís, MA & 295.655 & 24 \\
& Salvador, BA & 50.295 & 4 \\
& Barcarena, PA & 22.943 & 2 \\
\hline \multirow{2}{*}{ Piauí } & Vitória, ES & 6.254 & 1 \\
& Santos, SP & 224.561 & 64,1 \\
\hline \multirow{3}{*}{ Bahia } & São Luís, MA & 124.541 & 35,5 \\
& Salvador, BA & 1.361 & 0,4 \\
& Barcarena, PA & 1.499 .435 & 87 \\
& Salvador, BA & 142.392 & 8 \\
& Ilhéus, BA & 66.966 & 4 \\
& Vitória - ES & 11.979 & 0,7 \\
& São Luís - MA & 3.952 & 0,28 \\
\hline
\end{tabular}

Fonte: MDIC (2015)

No escoamento da soja para os portos da Bahia é utilizado, predominantemente, o modal rodoviário pela BR-242, que liga o interior ao litoral do estado. A soja com destino ao porto de Itaqui - MA conta com rotas rodoviárias, pelas BR-230, BR-135 e BR-235 no Piauí e Leste do Maranhão e rotas ferroviárias, pela Ferrovia Norte-Sul, por meio dos terminais de Porto Nacional e Palmeirante no Tocantins e de Porto Franco, no Oeste do Maranhão (CNT, 2015).

\section{O Modal Ferroviário de Cargas no Brasil}

No Brasil o transporte ferroviário teve sua origem entre os anos 1850 e 1900, quando foram criadas as primeiras rotas comerciais, principalmente para o transporte do café, no estado de São Paulo. Desde então o país registrou uma grande evolução na produção de commodities, tornando-se destaque mundial na produção e exportação de minério de ferro, petróleo bruto, soja, café, carne e açúcar. Nesse mesmo período, porém, o investimento em ferrovias não acompanhou o crescimento da produção, ficando em segundo plano durante muitos anos da história brasileira, voltando a ser referenciado novamente somente na década de 90, mas principalmente entre 2002 e 2006, com modelo de concessão à iniciativa privada (Branco e Caixeta Filho, 2011).

O modal de transporte ferroviário é caracterizado pela locomoção de bens e pessoas através de linhas férreas, sendo altamente indicado para o transporte em longas distâncias de carga com grandes quantidades e de baixo valor agregado, como grãos, fertilizantes, derivados de petróleo, minério de ferro, produtos siderúrgicos, entre outros, com destaque para as commodities. Apesar do alto custo para sua implantação, o custo operacional da ferrovia é relativamente baixo por não requisitar grande volume de mão de obra e ter baixo consumo energético, podendo assim ofertar um valor de frete mais competitivo em relação a outros modais para o transporte de lotes em grandes volumes. Por outro lado, a ferrovia tem como desvantagens o longo tempo de viagem, baixa flexibilidade de rotas e alta exposição a furtos durante o transporte (Soares e Ribeiro, 2014).

A rede ferroviária do Brasil conta com cerca de $28.600 \mathrm{~km}$, concentrada principalmente nas regiões Sul e Sudeste, e com menor proporção na região Nordeste. Segundo pesquisa realizada pela Confederação Nacional do Transporte (CNT, 2015), o Brasil necessitaria de pelo menos $52.000 \mathrm{~km}$ de ferrovia para atender à atual demanda, onde já existem projetos para aproximadamente $11.000 \mathrm{~km}$ até 2040 (Miguel e Reis, 2015). Segundo dados do Departamento de Pesquisas e Estudos Econômicos (DEPEC, 2016), o modal ferroviário responde por cerca de $20 \%$ do transporte de cargas no Brasil, ante 61\% do modal rodoviário. Entre as mercadorias que mais utilizam o modal ferroviário, destacam-se o minério de ferro (62\%), os minerais $(18 \%)$ e os grãos $(9 \%)$, que corresponderam a $89 \%$ de todas as mercadorias transportadas em 2013, que representam 298.616 bilhões de tonelada por quilômetro útil [TKU].

Por ser um modal para transporte de grandes quantidades em longas distâncias, o custo do transporte ferroviário pode representar $50 \%$ do custo do transporte rodoviário em distâncias acima de $1.000 \mathrm{~km}$, tendo como preços entre $\mathrm{R} \$ 15,00$ a $\mathrm{R} \$ 26,00$ por 1.000 $\mathrm{t} \mathrm{km}^{-1}$, contra $\mathrm{R} \$ 35,00$ a $\mathrm{R} \$ 45,00$ por $1.000 \mathrm{t} \mathrm{km}^{-1}$ no modal rodoviário, que foi voltado ao transporte de menores quantidades e percursos mais curtos (DEPEC, 2016).

No caso da soja, apesar de apresentar todos os requisitos para a utilização do modal ferroviário, como 
o baixo valor agregado, a comercialização em grandes volumes e a necessidade em percorrer longas distâncias até os portos, ela é escoada predominantemente por rodovias no Brasil, sendo transportados $65 \%$ de toda a produção nacional por caminhões, contra $26 \%$ por ferrovias e $9 \%$ por hidrovias. A título de comparação, os Estados Unidos utilizam $20 \%$ do transporte rodoviário, $31 \%$ do ferroviário e $49 \%$ do hidroviário para o transporte da soja produzida no país (Castro, 2015).

O dinamismo na utilização de meios de transportes de larga escala no escoamento da soja realizado pelos Estados Unidos traz como consequência um custo de transporte quatro vezes menor que o brasileiro, que utiliza em sua maioria o modal rodoviário, onde o custo por tonelada para transportar a soja americana foi de R $\$$ 35,00 , enquanto no Brasil, esse custo pode chegar a $R \$$ 160,00 , reduzindo a competitividade da soja brasileira nos portos e os preços pagos aos produtores no interior no país (Correa e Ramos, 2010).

Além do maior custo em relação ao modal ferroviário, o transporte de soja via rodovia apresenta outras desvantagens operacionais como maiores riscos de acidentes, avarias na carga e atrasos devido às situações das estradas, filas e congestionamento de caminhões para a descarga nos portos além da escassez de mão de obra durante o período de pico no escoamento da safra, elevando ainda mais o custo do frete (Soares e Caixeta Filho, 1997). Por possuir baixo valor agregado e apresentar alto custo logístico, o preço do frete tem um grande impacto no valor final da soja, podendo representar $23 \%$ do preço de venda. Tal impacto deve-se a baixa qualidade da infraestrutura existente, a falta de opções para escoamento, como novas rotas ferroviárias em polos produtores e a má utilização dos meios hidroviários (CNT, 2015).

\section{O Modal Ferroviário do MATOPIBA}

Com apenas uma rota ferroviária em funcionamento no MATOPIBA e outras ainda em execução e planejamento, produtores e tradings, Agrex, Amaggi, Bunge, Cargill e Louis Dreyfus foram algumas, ficaram na dependência do transporte rodoviário, que sofreram com problemas de estradas e o alto custo de manutenção e combustível (Soares e Caixeta Filho, 1997; Bartolomeu et al., 2016). Apesar da morosidade para a conclusão das obras, o modal ferroviário instalado é visto como um alívio para o escoamento local, inclusive trazendo novos investimentos de indústrias de diversos ramos do agronegócio, sendo o meio de transporte fundamental para tal (Caixeta Filho, 2010), e as demais ferrovias em curso deverão complementar essa demanda por uma melhor estrutura logística.

Entre projetos e obras concluídas na região, a Ferrovia Norte-Sul é a única que está em funcionamento. A Ferrovia de Integração Oeste-Leste encontra-se em obras e a integração da Ferrovia Transnordestina à Ferrovia Norte-Sul em fase de licitação. Depois de concluídas, o MATOPIBA contará com malhas ferroviárias pelos quatro estados e com rotas para os portos de São Luís, Maranhão; Pecém, Ceará; Suape, Pernambuco e Ilhéus, Bahia.

\section{Ferrovia Norte-Sul [FNS]}

A única ferrovia em operação no MATOPIBA teve sua origem na década de 80 , e seu o projeto inicial previa um traçado entre Açailândia, Maranhão (interligando a FNS à Estrada de Ferro Carajás [EFC]) e Anápolis, Goiás. Foi construído o trecho de $215 \mathrm{~km}$ entre Açailândia e Porto Franco, Maranhão entre os anos de 1987 e 1996. Após esse período, a construção da ferrovia foi paralisada por anos, até que em 2006 a Valec - Engenharia, Construções e Ferrovias S.A, empresa pública vinculada ao Ministério dos Transportes e com função social de construir e explorar a infraestrutura ferroviária do Brasil, iniciou o processo de licitação para conceder os direitos de subconcessão do trecho de $719 \mathrm{~km}$ entre Açailândia a Palmas - TO. A subconcessão foi concretizada em 2007, onde a Vale S.A. foi a vencedora da licitação, criando a empresa Ferrovia Norte Sul S.A., que obteve, pelo prazo de 30 anos, os direitos e deveres de conservar, manter, monitorar e operar o trecho licitado entre Açailândia e Palmas, que teve as obras concluídas somente em 2010 (VALEC, 2012a).

No ano de 2011, a Vale criou a empresa Valor Logística Integrada [VLI], "holding" com participação das empresas Vale, Mitsui, FI-FGTS e Brookfield, para administrar a Ferrovia Norte-Sul entre Porto Nacional e Açailândia, bem como a Estrada de Ferro Carajás, concessão da Vale, onde a VLI possui direito de passagem, levando até o Porto de Itaqui - MA. Seguidas as obras, em 2014 foi inaugurado o trecho de $855 \mathrm{~km}$ ligando Porto Nacional à Anápolis - GO, conforme o projeto inicial. Ainda em fase de obras e estudos, a Valec pretende estender a ferrovia ligando ainda trechos entre Ouro Verde, Goiás e Rio Grande, Rio Grande do Sul, passando por terminais em São Paulo e Santa Catarina.

Foram construídos ao longo do trecho da FNS, nove polos de cargas visando a recepção e transferência de cargas para o transporte dos mais diversos tipos de mercadorias, onde por meio de licitações pelo período de 30 anos, as empresas vencedoras comprometeram-se a prestar serviços para terceiros, para que o acesso à ferrovia não seja restrito. Os terminais estão distribuídos conforme a Figura 2. 


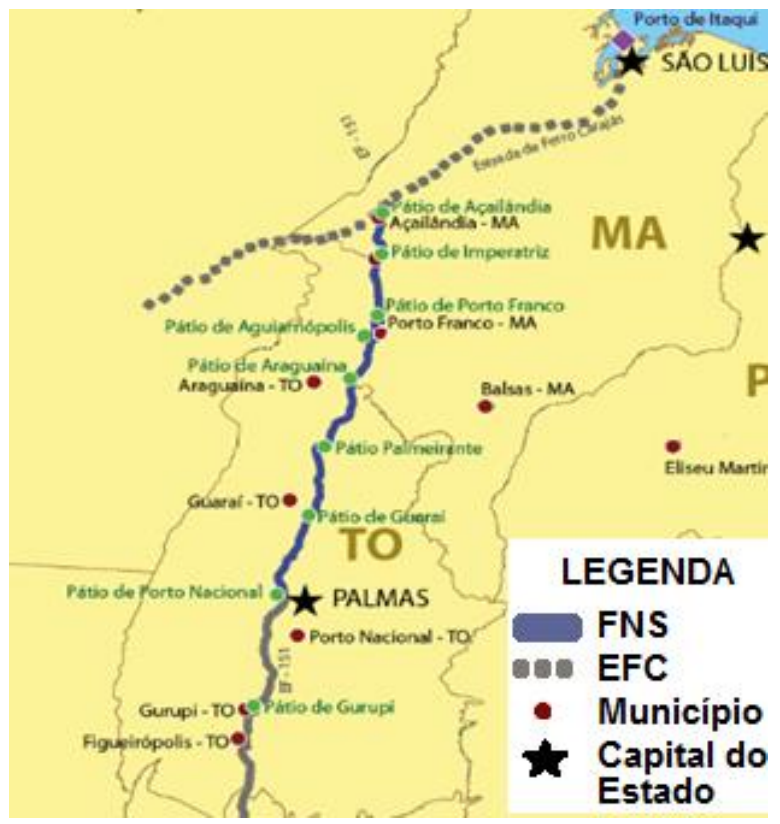

Figura 2. Polos de Carga Ferrovia Norte-Sul Fonte: VALEC (2012a)

Além dos polos de carga no trecho operado pela VLI foram inaugurados no início de 2016 dois terminais integradores [TI] para o recebimento e armazenagem de grãos nos municípios de Porto Nacional e Palmeirante, tendo como principais produtos a soja e o milho. O TI Porto Nacional e o TI Palmeirante contam juntos com uma capacidade estática de armazenagem de 150 mil toneladas, podendo receber um volume anual de 6 milhões de toneladas de grãos. Ambos são administrados pela VLI e contam com descarga de 40 caminhões por hora e capacidade de carregamento de um trem com 80 vagões em 4,5 horas (VLI, 2016).

Visando oferecer um melhor sistema logístico, a VLI escoou entre fevereiro e julho de 2015, mais de um milhão de toneladas e pretende aumentar esse volume para cinco milhões nos próximos anos, atendendo não só os estados do MATOPIBA, mas também estados vizinhos, como Pará, Mato Grosso e Goiás (Farias, 2016).

\section{Ferrovia de Integração Oeste-Leste [FIOL]}

Em obras desde 2011, a FIOL foi idealizada com o objetivo de fornecer novas alternativas logísticas ao interligar o interior do Brasil ao litoral da Bahia, transportando principalmente a produção local de grãos e minério de ferro até o Porto de Ilhéus, Bahia, visando substituir parte do transporte rodoviário pelo ferroviário e reduzir os custos de frete e o número de caminhões nas rodovias.

Com investimentos do Programa de Aceleração do Crescimento [PAC], o projeto da FIOL prevê uma extensão total de $1.527 \mathrm{~km}$, ligando Ilhéus à Ferrovia Norte-Sul, em Figueirópolis, Tocantins. Sua obra foi dividida pela Valec em três trechos (VALEC, 2015):

i. Ilhéus à Caetité: do litoral à região central da Bahia, com as obras iniciadas em 2011 e previsão de entrega para 2017;

ii. Caetité à Barreiras: do Centro ao Oeste Baiano, teve suas obras iniciadas em 2015, com previsão para conclusão em 2018, e;

iii. Barreiras à Figueirópolis: do extremo Oeste da Bahia ao Sul do Tocantins, o último trecho da ferrovia aguarda a licença do Instituto Brasileiro do Meio Ambiente e dos Recursos Naturais Renováveis [IBAMA] para a instalação das obras. Não há previsão para sua conclusão.

Assim como a FNS, a FIOL terá ao longo de seu percurso TI para o recebimento de cargas de acordo com cada polo de produção, como a mineração na região central da Bahia e a agropecuária no Oeste da Bahia e Sul do Tocantins (Figura 3).

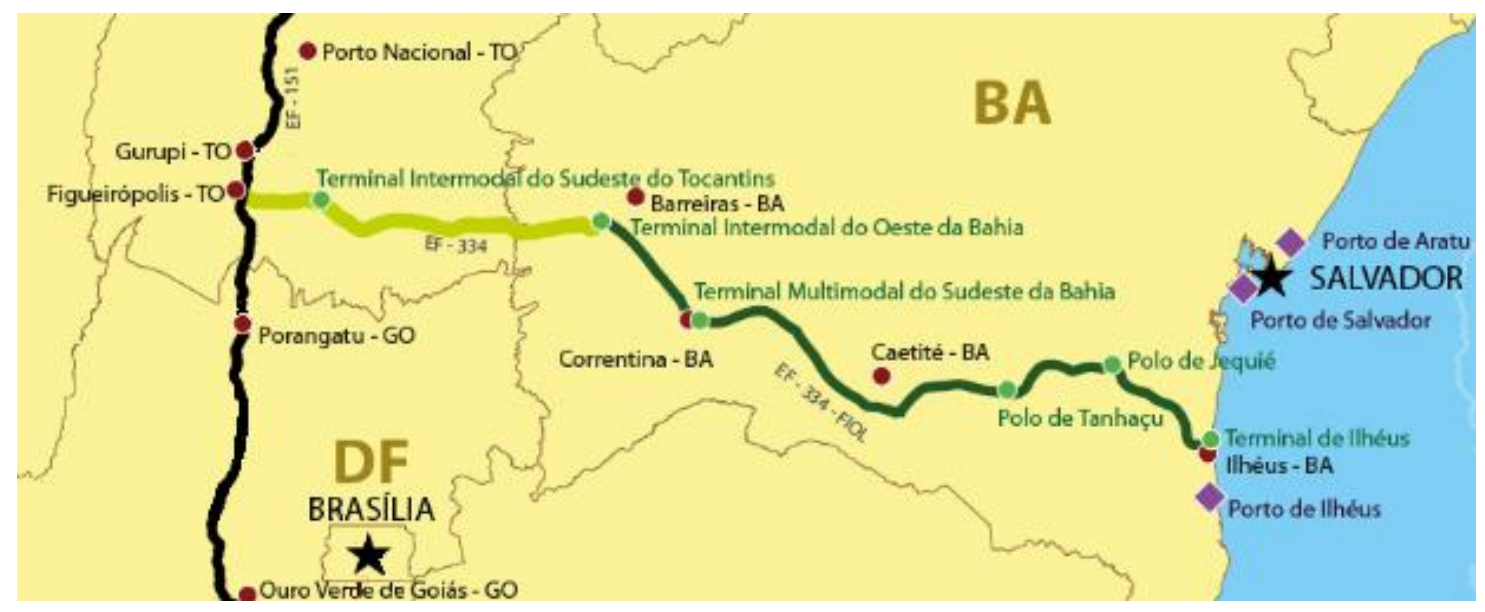

Figura 3. Polos de Carga da Ferrovia de Integração Oeste-Leste

Fonte: VALEC (2015) 
Visando expandir os investimentos, foram iniciados em 2016 negociações entre o Governo do Estado da Bahia, a Bahia Mineração, o Fundo Chinês "Clai-Fund" e a "China Railway Engineering Group", e, segundo termos em negociação, o fundo Chinês deverá investir na construção e operação da FIOL e do projeto Porto Sul, complexo portuário a ser construído no município de Ilhéus, somando um investimento estimado em $\mathrm{R} \$$ 2,6 bilhões. Depois de concluído, o grupo chinês pretende ainda estender a Ferrovia Oeste Leste, criando a Ferrovia Bioceânica, cortando o Brasil de Leste a Oeste e ligando os Oceanos Atlântico e Pacífico, a partir de Ilhéus até o Peru (SECOMBA, 2016).

\section{Ferrovia Transnordestina}

Devido às crescentes demandas da nova fronteira agrícola para o escoamento de grãos do MATOPIBA e a indústria de minérios do Piauí e Pernambuco, a Ferrovia Transnordestina foi projetada a partir de 2002 visando atender parte dessa demanda, transportando a produção da região aos principais portos do Nordeste brasileiro e importando insumos de outros países, como fertilizantes e combustíveis, que são muito utilizados na agricultura nacional (ANTF, 2011).

Em obras desde 2006, a previsão de conclusão da ferrovia que inicialmente era para 2010 não foi concretizada e em 2016 a obra encontra-se inacabada e sem data exata para sua finalização, com previsões de entrega entre 2017 e 2018 pela empresa transnordestina logística S.A. [TLSA], responsável pela ferrovia e subsidiária da Companhia Siderúrgica Nacional [CSN]. Além dos atrasos e prazos prorrogados, a revisão do valor previsto para a conclusão da ferrovia aumentou em $150 \%$ comparada às previsões iniciais, ao lançamento do projeto. Apesar de ser um empreendimento de iniciativa privada, a ferrovia recebe aportes financeiros de recursos públicos, como do PAC, do Banco Nacional de Desenvolvimento Econômico e Social Participações [BNDESPar], do Fundo de Desenvolvimento do Nordeste e da Valec.

O projeto da Transnordestina visa ligar a região Sul do Piauí, a partir do município de Eliseu Martins, aos portos de Pecém, Ceará e Suape, Pernambuco. Contando com $1.753 \mathrm{~km}$ de ferrovia, o projeto é de extrema importância e necessidade para o transporte de soja da maior região produtora do Piauí, que conta hoje somente com a opção de transporte rodoviário para o escoamento da safra (Sousa, 2015).

Partindo do traçado original da Transnordestina, a Valec realizou um projeto de interligação entre as Ferrovias Transnordestina e FNS, alongando a ferrovia de Eliseu Martins ao Terminal de Porto Franco, Maranhão, em um percurso de $620 \mathrm{~km}$, que deverá aumentar as possibilidades de escoamento de soja das regiões Sul do Maranhão e Piauí e Norte do Tocantins, tanto pelo Porto de Itaqui, quanto por Fortaleza e Suape, conforme a Figura 4 (VALEC, 2012b).

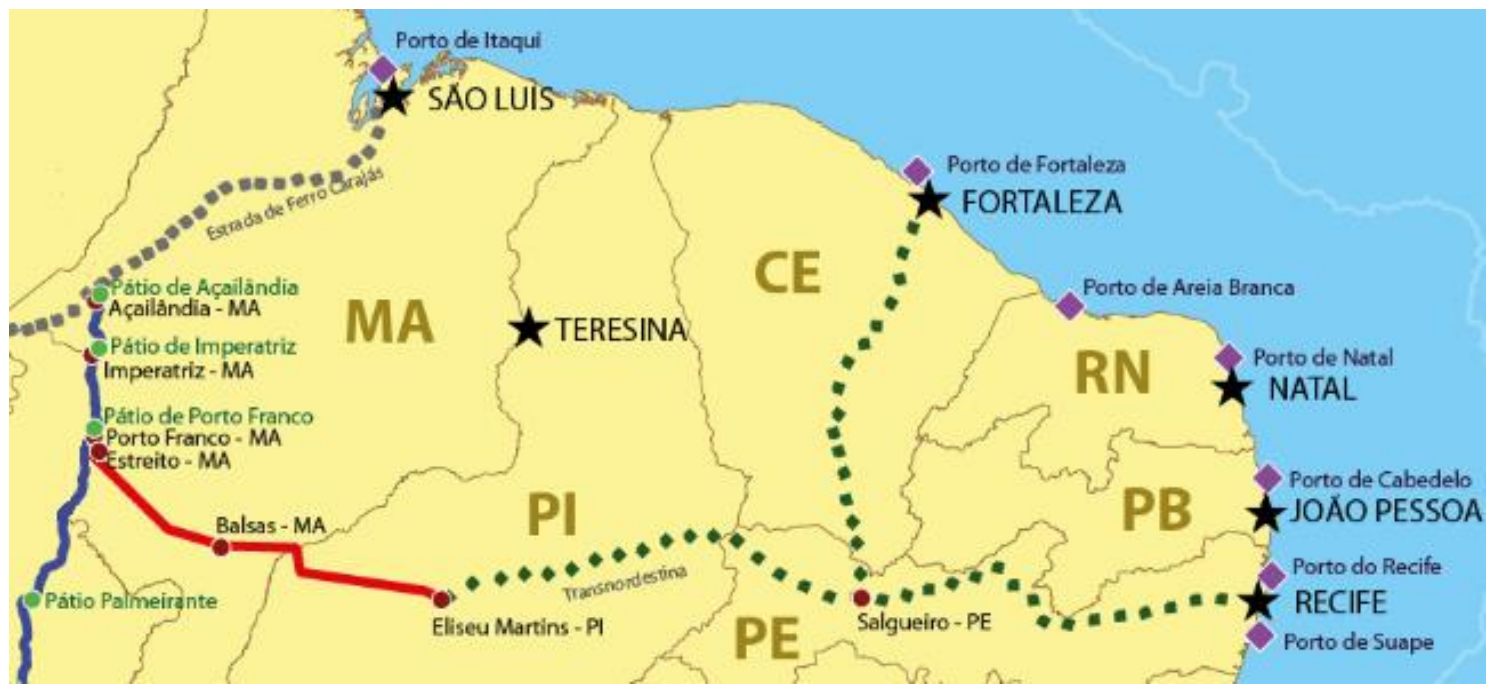

Figura 4. Ferrovia Transnordestina e ligação com a Ferrovia Norte-Sul Fonte: Valec (2012b)

Depois de finalizadas as obras, a infraestrutura logística do MATOPIBA passará a ter o modal ferroviário como base onde a Ferrovia Norte-Sul será o eixo principal de toda a malha, sendo o corredor de maior volume a ser escoado na região, e possibilitará a interligação entre as ferrovias Transnordestina e a de Integração Oeste-Leste (Eid, 2016). O MATOPIBA contará com aproximadamente $5.000 \mathrm{~km}$ de ferrovias, com rotas e terminais de recepção de cargas pelos quatro estados, cortando as principais regiões produtoras de cada estado 


\section{Conclusões}

O agronegócio no MATOPIBA apresenta crescentes resultados na produção agrícola e boas perspectivas de crescimento para os próximos anos, atraindo diversos investimentos para o setor. Entretanto, apesar de benefícios climáticos e técnicos para a produção de grãos, a região perde competitividade devido aos problemas logísticos no escoamento da safra, realizado predominantemente pelo modal rodoviário.

Contudo, o avanço e a atual situação dos projetos ferroviários no MATOPIBA interligarão todas as regiões produtoras a portos do Norte/Nordeste, de maneira que o escoamento de soja para exportação realizado via ferrovias possibilitará obter benefícios frente ao modal rodoviário devido as suas características físicas e operacionais.

Além dos benefícios do transporte ferroviário, ainda há entraves que precisam ser superados, como a dependência do modal rodoviário para o transporte da soja e o atraso das obras nas ferrovias em decorrência de problemas burocráticos e à falta de recursos público e privado.

\section{Referências}

Alves, V.E.L. 2014. Región centro-norte de Brasil: dinámicas territoriales recientes en el campo y en la ciudad. Cuadernos de Geografía 23(1): 47-60.

Associação Brasileira das Indústrias de Óleos Vegetais [ABIOVE]. 2015. Pesquisa de Capacidade Instalada da Indústria de Óleos Vegetais - 2014. Disponível em: <http://www.abiove.org.br/site/index.php?page=est atistica\&area $=\mathrm{NCOyLTE}=>$. Acesso em: 13 ago. 2016.

Associação Nacional dos Transportadores Ferroviários [ANTF]. 2011. Apresentação Transnordestina Logística S.A. Disponível em: <http://www.antf.org.br/pdfs/transnordestinainstitucional.pdf>. Acesso em: 03 set. 2016.

Barbosa, E.L; Monteiro, M.S.L; Silva, A.J. 2015. Nova dinâmica produtiva e velhas questões territoriais nos cerrados setentrionais do Brasil. Revista Espacios 36 (21): 14-21.

Bartholomeu, D.B.; Péra, T.G.; Caixeta Filho, J.V. 2016. Logística sustentável: avaliação de estratégias de redução das emissões de $\mathrm{CO}_{2}$ no transporte rodoviário de cargas. Journal of Transport Literature 10(3): 15-19.

Branco, J.E.H.; Caixeta Filho, J.V. 2011. Estimativa da demanda de carga captável pela estrada de ferro Norte-Sul. Journal of Transport Literature 5(4): 17-50.

Branco, J.E.H.; Caixeta Filho, J.V.; Xavier, C.E.O.; Lopes, R.L.; Gameiro, A.H. 2010. Informe Gepec 14(1): 84-100.
Brasil. 2015. "MATOPIBA" se consolida como nova fronteira agrícola do País. Disponível em: <http://www.brasil.gov.br/economia-eemprego/2015/10/matopiba-se-consolida-comonova-fronteira-agricola-do-pais $>$. Acesso em: 10 jul. 2016.

Caixeta Filho, J.V. 2010. Logística para a agricultura brasileira. Revista Brasileira de Comércio Exterior 103: 18-30.

Castro, C. 2015. Bilhões desperdiçados. Edição Informativa da CNT 237: 20-24.

Companhia Nacional de Abastecimento [CONAB]. 2011. Acompanhamento da safra brasileira: grãos, décimo segundo levantamento. Disponível em: <http://www.conab.gov.br/OlalaCMS/uploads/arqu ivos/11_09_19_09_49_47_boletim_setembro2011.pdf>. Acesso em: 30 jul. 2016.

Companhia Nacional de Abastecimento [CONAB]. 2016. Acompanhamento da safra brasileira: grãos, décimo levantamento. Disponível em:

<http://www.conab.gov.br/OlalaCMS/uploads/arqu ivos/16_07_07_14_37_20_boletim_graos_julho_201 6.pdf>. Acesso em: 30 jul. 2016.

Confederação Nacional dos Transportes [CNT]. 2015. Entraves logísticos ao escoamento de soja e milho. Disponível em:

<http://www.cnt.org.br/Paginas/Pesquisas_Detalhes .aspx?p=15>. Acesso em: 11 set. 2016.

Correa, V.H.C.; Ramos, P. 2010. A precariedade do transporte rodoviário brasileiro para o escoamento da produção de soja do Centro-Oeste: situação e perspectivas. Revista de Economia e Sociologia Rural 48(2): 447-472. doi: 10.1590/S0103-

20032010000200009

Departamento de Pesquisas e Estudos Econômicos [DEPEC]. 2016. Transporte Ferroviário. Disponível em:

$<$ http://www.economiaemdia.com.br/EconomiaEm $\mathrm{Dia} / \mathrm{pdf} /$ infset_transporte_ferroviario.pdf $>$. Acesso em: 10 set. 2016 .

Eid, C. 2016. Ocupação sustentável do território nacional pela ferrovia/agronegócio. Jornal do Instituto de Engenharia 89: 3.

Empresa Brasileira de Pesquisa Agropecuária [EMBRAPA]. 2015. MATOPIBA. Disponível em: <https://www.embrapa.br/gite/projetos/matopiba/ 150319_MATOPIBA_SENADO_website.pdf $>$. Acesso em: 30 jul. 2016.

Farias, F. 2015. Cadeia produtiva do Tocantins quer mais investimentos em ferrovias. Disponível em: $<$ http://www.projetosojabrasil.com.br/cadeiaprodutiva-de-tocantins-quer-mais-investimentos-emferrovias/>. Acesso em: 20 ago. 2016.

Miguel, P.L.S; Reis, M.A.S. 2015. Panorama do transporte ferroviário no Brasil. Mundo Logística 47: 16-22. 
Matos, P.F.; Pessôa, V.L.S. 2011. A modernização da agricultura no Brasil e os novos usos do território. Geo UFRJ 2(22): 290-322.

Ministério da Agricultura, Pecuária e Abastecimento [MAPA]. 2015. Projeções do Agronegócio. Brasil 2014/15 a 2024/25. Disponível em:

<http://www.agricultura.gov.br/arq_editor/PROJE COES_DO_AGRONEGOCIO_2025_WEB.pdf $>$. Acesso em: 10 jul. 2016.

Ministério do Desenvolvimento, Indústria e Comércio Exterior [MDIC]. 2015. AliceWeb, Consulta NCM 12019000. Disponível em: $<$ http://aliceweb.mdic.gov.br//consulta$\mathrm{ncm} /$ index/type/exportacaoNcm $>$. Acesso em: 13 ago. 2016.

Missão, M.R. 2006. Soja: Origem, classificação, utilização e uma visão abrangente do mercado. Maringá Management: Revista de ciências empresariais 3 (1): 7-15.

Secretaria da Agricultura e Pecuária [SEAGRO]. 2015. Com incentivo do Estado, agronegócio se expande no Tocantins e atrai empresários. Disponível em: <http://seagro.to.gov.br/noticia/2015/4/28/comincentivo-do-estado-agronegocio-se-expande-notocantins-e-atrai-empresarios/>. Acesso em: 27 ago. 2016.

Secretaria de Comunicação Social da Bahia [SECOM]. 2016. Grupo chinês vai investir na construção e operação do Porto Sul e Fiol. Disponível em: <http://www.secom.ba.gov.br/2016/03/131119/Gr upo-chines-vai-investir-na-construcao-e-operacao-doPorto-Sul-e-Fiol.html>. Acesso em: 25 ago. 2016.

Silva, A.J. da; Monteiro, M. do S.L.; Barbosa, E.L. 2015. Difusão do agronegócio no Brasil: estratégias governamentais. Informe Econômico 17(34): 47-54. Soares, M.G.; Caixeta Filho, J.V. 1997. Caracterização do mercado de fretes rodoviários para produtos agrícolas. Gestão \& Produção 4(2): 186-204.

Soares, J.B.C; Ribeiro, I.O.C.A. 2014. Transporte ferroviário: a solução para o escoamento da produção de soja de Mato Grosso sentido Porto de Santos. Periódico Científico Negócios em Projeção 5: 50-52.

Souza, S. 2015. Orçamento da ferrovia salta $150 \%$ em 5 anos. Disponível em:

<http://diariodonordeste.verdesmares.com.br/cader nos/negocios/orcamento-da-ferrovia-salta-150-em-5anos-1.1267603>. Acesso em: 03 set. 2016.

Valec Engenharia, Construções e Ferrovias S.A. 2012a. EF-151 - Ferrovia Norte-Sul-FNS. Disponível em: <http://www.valec.gov.br/acoes_programas/FNSFe rroviaNorteSul.php>. Acesso em: 20 ago. 2016.

Valec Engenharia, Construções e Ferrovias S.A. 2012b. EF-232 - Ligação da FNS com a Transnordestina. Disponível em: <http://www.valec.gov.br/acoes_programas/LFNS TPortoFrancoEliseuMartins.php $>$. Acesso em: 03 set. 2016.
Valec Engenharia, Construções e Ferrovias S.A. 2015. EF-334 - Ferrovia de Integração Oeste Leste - FIOL. Disponível em:

<http://www.valec.gov.br/acoes_programas/Ferrovi aIntegracaoOesteLeste.php>. Acesso em: 25 ago. 2016.

Valor Logística Integrada S.A. [VLI]. 2016. Terminais. Disponível em: < http://www.vli-logistica.com/ptbr/conheca>. Acesso em: 20 ago. 2016. 